\title{
Survival and mortality of elderly men with localized prostate cancer managed with primary androgen deprivation therapy or by primary observation
}

Heikki Seikkula ${ }^{1 *}$, Peter J. Boström ${ }^{2,3}$, Karri Seppä ${ }^{4}$, Janne Pitkäniemi ${ }^{4,5,6}$, Nea Malila ${ }^{4,7}$ and Antti Kaipia ${ }^{8}$

\begin{abstract}
Background: Androgen deprivation therapy (ADT) remains a primary treatment for localized prostate cancer (PCa) even though there is no evidence that its use is beneficial in the absence of curative treatment.

Methods: Men aged $\geq 70$ years ( $n=16,534$ ) diagnosed with localized PCa from 1985 to 2014 and managed either with primary observation or ADT in the absence of curative treatment were included. The cases were identified from the population-based Finnish Cancer Registry. We estimated the standardized mortality ratios (SMR) for overall mortality by treatment group. We determined the relative risk (RR) of PCa-specific mortality (PCSM) and other-cause mortality between the two treatment groups. Survival was determined using the life table method. Two age groups (70-79years and $\geq 80$ years) and three calendar time cohorts (1985-1994, 1995-2004, and 2005-2014) were compared following adjustment of propensity score matching between the treatment groups with four covariates (age, year of diagnosis, educational level, and hospital district). Follow-up continued until death or until December 31, 2015.

Results: Patients in the observation group had lower overall SMRs than those in the ADT group in both age cohorts over the entire study period. PCSM was higher in men aged 70-79years undergoing primary ADT compared to those managed by observation only (RR: 1.70, 95\% confidence interval [Cl]: 1.29-2.23 [1985-1994]; RR 1.55, 95\% Cl: 1.35-1.84 [1995-2004]; and RR 2.71, 95\% Cl: 2.08-3.53 [2005-2014]); $p=0.005$ for periodic trend. A similar trend over time was also observed in men aged $>80$ years; ( $p$ for age-period interaction $=0.237$ ). Overall survival was also higher among men in their 70's managed by observation compared to those undergoing ADT.

Conclusions: Primary ADT within four months period from diagnosis is not associated with improved long-term overall survival or decreased PCSM compared to primary conservative management for men with localized PCa. However, this observational study's conclusions should be weighted with confounding factors related to cancer aggressiveness and comorbidities.
\end{abstract}

Keywords: Prostate cancer survival, Prostate cancer-specific mortality, Localized prostate cancer, Androgen deprivation therapy

\footnotetext{
* Correspondence: heikki.seikkula@ksshp.fi

'Department of Surgery, Central Hospital of Central Finland, Jyväskylä, Finland

Full list of author information is available at the end of the article
}

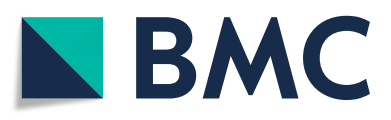

() The Author(s). 2020 Open Access This article is licensed under a Creative Commons Attribution 4.0 International License, which permits use, sharing, adaptation, distribution and reproduction in any medium or format, as long as you give appropriate credit to the original author(s) and the source, provide a link to the Creative Commons licence, and indicate if changes were made. The images or other third party material in this article are included in the article's Creative Commons licence, unless indicated otherwise in a credit line to the material. If material is not included in the article's Creative Commons licence and your intended use is not permitted by statutory regulation or exceeds the permitted use, you will need to obtain permission directly from the copyright holder. To view a copy of this licence, visit http://creativecommons.org/licenses/by/4.0/ The Creative Commons Public Domain Dedication waiver (http://creativecommons.org/publicdomain/zero/1.0/) applies to the data made available in this article, unless otherwise stated in a credit line to the data. 


\section{Background}

Androgen deprivation therapy (ADT) has been the cornerstone of treatment for locally advanced and metastatic $(\mathrm{M}+)$ prostate cancer $(\mathrm{PCa})$ since the 1940s [1]. Immediate ADT or ADT combined with docetaxel or abiraterone acetate is the current treatment of choice for $\mathrm{M}+\mathrm{PCa}$ [2]. However, the use of ADT increased sharply between 1989 and 2001 in the USA despite the fact that $\leq 5 \%$ of patients with newly diagnosed $\mathrm{PCa}$ have distant metastases at first presentation compared with $20-25 \%$ $\geq 20$ years ago [3, 4]. While the increased use of ADT is partly accounted for by the uptake of neoadjuvant and adjuvant treatment along with radiation therapy, it is primarily elucidated by ADT for localized disease, especially for elderly patients [5]. Thus, ADT is commonly used to treat localized $\mathrm{PCa}$ although it has not been shown to improve survival [6].

The risk of metastases or death from conservatively managed clinical stage T1/T2 cancers was estimated in a meta-analysis of six studies from the era prior to prostate-specific antigen (PSA) [7]. The risk of metastasis at 10 years was found to be 19,42 , and $74 \%$ for welldifferentiated, moderately differentiated, and poorly differentiated tumors, respectively [7]. Similarly, the longterm clinical outcomes of localized PCa without initial treatment with curative intent during the PSA era were assessed [8]. Thirty per cent of the patients died of PCa and $30 \%$ of other causes within a 12-year period [8]. A landmark Swedish study demonstrated a benign course of well- or intermediately differentiated $\mathrm{PCa}$ in the absence of initial treatment with curative intent [9]. Thus, the clinical course of localized high-risk PCa can be progressive, but the majority of cancers are indolent and slow to progress [2]. According to current guidelines, observation with the option of later treatment in the case of disease progression (i.e., watchful waiting) is recommended for localized and locally advanced $\mathrm{PCa}$ in elderly patients with competing comorbidities.

The objective of this observational study was to investigate mortality in elderly $\mathrm{PCa}$ patients primarily managed with ADT or observation only during long followups in Finland.

\section{Methods}

\section{Study population}

The Finnish Cancer Registry is a nationwide populationbased register of all incident cancer cases diagnosed in Finland since 1953. The health care personnel in hospitals, outpatient clinics, and healthcare facilities are obligated to notify of new cases. Additionally, pathology notifications are received from all histopathological laboratories in Finland. The registry coverage is estimated at $99 \%$ for male genital cancers [10]. The spreading into localized, locally advanced, or metastatic are classified by tumor size, regional node involvement, and presence of metastasis for cases covered by the Finnish Cancer Registry.

The Finnish Cancer Registry data can be linked with the population register center database for dates of death or emigration and causes of death and education levels from Statistics Finland.

We identified all PCa patients aged 70 years or older at diagnosis with localized cancer (clinical stage T1/T2) from 1985 to 2014 and managed by primary ADT or observation in the absence of radical treatment with curative intent (Table 1). Of the total patients identified $(n=$ 16,534), 11,572 were aged 70-79 years and 4962 were $\geq$ 80. Within four months of diagnosis, the primary treatment was ADT (ADT group $n=9704$ ), while 6830 received no treatment (observation group) (Table 1). The regional data included 22 hospital districts taking care of specialized care. The survival rates of the patients were compared by age and treatment group over three periods (1985-1994, 1995-2004, and 2005-2014).

\section{Statistical analysis}

Overall survival was evaluated using the life table method [11]. The Poisson regression model was used to quantify differences in patient mortality between the defined groups. The results were reported as relative risk (RR) of PCa-specific mortality (PCSM) and mortality due to causes other than PCa. We also estimated the standardized mortality ratio (SMR) for overall mortality among the patients. The SMR is estimated as the ratio of observed and expected numbers of deaths. The latter was derived from the mortality rates of the male population in Finland stratified by age (1-year intervals), calendar year and education. We used a nearest neighbor matching with a logistic regression-based propensity score [12] to identify a cohort of 5715 paired patients. In the logistic regression, the probability of a given treatment was modeled as a function of age and calendar period (in 5-year groups), education, and hospital district. Interactions between calendar period and each of the covariates were also included in the model. Statistical analysis was performed with $\mathrm{R}$ (version 3.2.3) using the packages popEpi [13] and MatchIt [14].

The study protocol was approved by the institutional review board of the Hospital District of Southwest Finland. The National Institute for Health and Welfare (Finland) approved access to the registry data (study number 182/5.05.00/2015). Statistics Finland approved access to the data on the cause of death (study number TK-53-86-17).

\section{Results}

The stage distribution of all prostate cancer patients from 1985 to $2014(n=95,959)$ in Finland is shown in 
Table 1 Study population of prostate cancer patients

\begin{tabular}{|c|c|c|c|c|}
\hline \multirow[b]{3}{*}{ Variable } & \multicolumn{4}{|c|}{ All patients } \\
\hline & \multicolumn{2}{|l|}{ ADT } & \multicolumn{2}{|c|}{ Observation } \\
\hline & $\mathrm{N}$ & $\%$ & $\mathrm{~N}$ & $\%$ \\
\hline \multicolumn{5}{|l|}{ Age at diagnosis } \\
\hline $70-74$ & 3096 & 31.9 & 2850 & 41.7 \\
\hline $75-79$ & 3411 & 35.2 & 2215 & 32.4 \\
\hline $80-84$ & 2170 & 22.4 & 1227 & 18.0 \\
\hline $85-89$ & 832 & 8.6 & 438 & 6.4 \\
\hline$>90$ & 195 & 2.0 & 100 & 1.5 \\
\hline Total & 9704 & 100 & 6830 & 100 \\
\hline \multicolumn{5}{|l|}{ Year of diagnosis } \\
\hline 1985-1989 & 785 & 8.1 & 208 & 3.0 \\
\hline 1990-1994 & 1197 & 12.3 & 337 & 4.9 \\
\hline 1995-1999 & 1724 & 17.8 & 797 & 11.7 \\
\hline 2000-2004 & 2159 & 22.2 & 1313 & 19.2 \\
\hline 2005-2009 & 2280 & 23.5 & 2194 & 32.1 \\
\hline 2010-2014 & 1559 & 16.1 & 1981 & 29.0 \\
\hline Total & 9704 & 100 & 6830 & 100 \\
\hline \multicolumn{5}{|l|}{ Education level } \\
\hline Basic & 6920 & 71.3 & 4421 & 64.7 \\
\hline Secondary & 1325 & 13.7 & 1074 & 15.7 \\
\hline High & 1459 & 15.0 & 1335 & 19.5 \\
\hline Total & 9704 & 100 & 6830 & 100 \\
\hline \multicolumn{5}{|l|}{ Hospital district } \\
\hline Uusimaa & 932 & 9.6 & 786 & 11.5 \\
\hline Helsinki & 812 & 8.4 & 698 & 10.2 \\
\hline Varsinais-Suomi & 835 & 8.6 & 628 & 9.2 \\
\hline Satakunta & 500 & 5.2 & 281 & 4.1 \\
\hline Kanta-Hame & 471 & 4.9 & 322 & 4.7 \\
\hline Pirkanmaa & 1187 & 12.2 & 614 & 9.0 \\
\hline Paijat-Hame & 668 & 6.9 & 304 & 4.5 \\
\hline Kymenlaakso & 433 & 4.5 & 182 & 2.7 \\
\hline Etela-Karjala & 321 & 3.3 & 179 & 2.6 \\
\hline Etela-Savo & 158 & 1.6 & 102 & 1.5 \\
\hline Ita-Savo & 76 & 0.8 & 64 & 0.9 \\
\hline Pohjois-Karjala & 149 & 1.5 & 178 & 2.6 \\
\hline Pohjois-Savo & 466 & 4.8 & 403 & 5.9 \\
\hline Keski-Suomi & 374 & 3.9 & 557 & 8.2 \\
\hline Etela-Pohjanmaa & 522 & 5.4 & 386 & 5.7 \\
\hline Vaasa & 285 & 2.9 & 182 & 2.7 \\
\hline Keski-Pohjanmaa & 136 & 1.4 & 128 & 1.9 \\
\hline Pohjois-Pohjanmaa & 610 & 6.3 & 372 & 5.4 \\
\hline Kainuu & 265 & 2.7 & 99 & 1.4 \\
\hline Lansi-Pohja & 280 & 2.9 & 132 & 1.9 \\
\hline Lappi & 190 & 2.0 & 177 & 2.6 \\
\hline
\end{tabular}

Table 1 Study population of prostate cancer patients (Continued)

\begin{tabular}{|c|c|c|c|c|}
\hline \multirow[b]{3}{*}{ Variable } & \multicolumn{4}{|c|}{ All patients } \\
\hline & \multicolumn{2}{|l|}{ ADT } & \multicolumn{2}{|c|}{ Observation } \\
\hline & $\bar{N}$ & $\%$ & $\bar{N}$ & $\%$ \\
\hline Åland & 34 & 0.4 & 56 & 0.8 \\
\hline Total & 9704 & 100 & 6830 & 100 \\
\hline
\end{tabular}

Supplementary Table 1. Approximately half of the patients were classified as having localized $\mathrm{PCa}$. The proportion of metastatic disease decreased from 28 to $17 \%$ between the periods 1985-1994 and 2005-2014. However, the PCa stage was missing in nearly one-third of the patients over the study period (Supplementary Table 1). In this study, we included only PCa patients aged 70 years or older at diagnosis who received primary treatment with ADT or no treatment within four months of diagnosis (Table 1).

SMR analysis showed that overall mortality was lower in the observation group than in the ADT group in all three time periods. However, a declining trend in SMR over time was seen in both groups. Furthermore, over the most recent period (2005-2014), patients in both age cohorts had lower overall mortality than the general male population in Finland (SMR: 0.93, 95\% CI: 0.880.98) (Table 2). Propensity score matching did not change any of these results.

In both age cohorts, we observed higher PCSM in patients undergoing primary ADT compared to those managed by observation only (Table 3 ). The relative risk of prostate cancer mortality increased significantly over time in the ADT group compared to the observation group ( $p$ for trend $=0.05$ ). On the other hand, the risk of death from causes other than PCa decreased over time in patients aged 70-79 years undergoing primary ADT compared to those managed by observation only, but the same was not true in patients aged 80 years or older (Table 3).

Overall survival of PCa patients aged 70-79 years was higher in the observation group than in the ADT group throughout the study period. However, a rising trend was observed in both treatment groups. Among patients over 80 years of age, overall survival improved over time in both treatment groups with no significant differences between them until the most recent period (from 2005 to 2014), when overall survival in the observation group was higher than in the ADT group (Fig. 1). The results remained similar after propensity score matching.

\section{Discussion}

In this population-based study, we investigated whether the survival and mortality outcomes in elderly male 
Table $\mathbf{2}$ Overall mortality of the study patients compared to that of the male population of Finland

\begin{tabular}{|c|c|c|c|c|c|c|}
\hline \multirow[t]{3}{*}{ All patients } & \multicolumn{6}{|l|}{ Period } \\
\hline & \multicolumn{2}{|l|}{ 1985-1994 } & \multicolumn{2}{|l|}{$1995-2004$} & \multicolumn{2}{|l|}{ 2005-2014 } \\
\hline & ADT & Observation & ADT & Observation & ADT & Observation \\
\hline Age & \multicolumn{6}{|c|}{ SMR (95\% confidence interval) } \\
\hline All (> 70) & $1.48(1.41-1.54)$ & $1.20(1.10-1.30)$ & $1.19(1.15-1.23)$ & $1.03(0.98-1.08)$ & $1.08(1.03-1.13)$ & $0.93(0.88-0.98)$ \\
\hline 70-79 & $1.57(1.48-1.65)$ & $1.17(1.05-1.30)$ & $1.24(1.19-1.29)$ & $1.05(0.99-1.11)$ & $1.11(1.04-1.19)$ & $0.95(0.88-1.01)$ \\
\hline$\geq 80$ & $1.39(1.22-1.42)$ & $1.25(1.08-1.43)$ & $1.10(1.04-1.17)$ & $1.00(0.92-1.09)$ & $1.04(0.97-1.11)$ & $0.89(0.82-0.97)$ \\
\hline \multicolumn{7}{|c|}{ Matched pairs } \\
\hline All $(>70)$ & $1.50(1.38-1.63)$ & $1.19(1.09-1.30)$ & $1.19(1.13-1.25)$ & $1.03(0.98-1.08)$ & $1.09(1.03-1.15)$ & $0.93(0.87-0.98)$ \\
\hline $70-79$ & $1.57(1.41-1.74)$ & $1.16(1.04-1.29)$ & $1.23(1.16-1.30)$ & $1.05(0.99-1.11)$ & $1.12(1.05-1.20)$ & $0.94(0.87-1.01)$ \\
\hline$\geq 80$ & $1.39(1.21-1.60)$ & $1.25(1.08-1.44)$ & $1.12(1.02-1.21)$ & $1.00(0.91-1.08)$ & $1.03(0.94-1.12)$ & $0.91(0.82-0.99)$ \\
\hline
\end{tabular}

Population mortality stratified by age and calendar year and education level

$A D T$ androgen deprivation therapy, SMR standardized mortality ratio

patients (aged $\geq 70$ years) with localized $\mathrm{PCa}$ is different between those managed by primary observation and those undergoing primary ADT over a long period of time. We showed that the overall SMR of patients in the observation cohort was lower than those in the ADT cohort in both age groups over the entire study period. PCSM and mortality due to causes other than PCa were lower in patients monitored with primary observation compared to those managed with primary ADT. This difference was particularly evident in patients aged 7079 years at the time of diagnosis. Overall survival was also higher in subjects in this age group managed by primary observation. By contrast, a smaller difference in PSCM was observed between patients undergoing ADT and those managed by primary observation, while a clear difference in mortality due to other causes was not seen in patients aged 80 or older. This implies a better general health condition and a healthier lifestyle among patients in the observation cohort.

An increased risk of PCSM was observed in patients undergoing primary ADT compared to those managed by primary observation, while a lower risk of other-cause mortality was seen in the younger patient group managed by primary observation. This suggests that in recent times, primary ADT without curative treatment was generally selected for patients with aggressive disease. A 10-year threefold risk of PCSM was associated with poorly differentiated $\mathrm{PCa}$ among patients with conservatively managed localized PCa in the Surveillance, Epidemiology, and End Results (SEER) Program [15]. Most male patients with conservatively managed localized $\mathrm{PCa}$ aged $>66$ years with competing comorbidities died from causes other than PCa in a period of 10 years, irrespective of age and tumor aggressiveness [16]. The use of primary ADT was beneficial for patients with aggressive disease and few comorbidities [16]. However, overall mortality was lower in subjects managed by observation than with ADT. We assumed that a shift from ADT to a more radical treatment may have occurred in patients with a good general health status. Since an increasing number of PCa cases has been diagnosed in recent years, and observation is widely utilized in Finland, it is likely that observation was selected for patients with less aggressive histology and without advanced disease. Consequently, fewer male patients died of cancer owing to the slow, natural course of disease.

Overall survival was reduced in patients aged 70-79 years initially treated with. It is still difficult to draw a

Table 3 Risk of PCa and other-cause mortality among men on primary ADT compared to observation only

\begin{tabular}{|c|c|c|c|c|}
\hline \multirow[t]{2}{*}{ Time period (age) } & \multicolumn{2}{|c|}{ Relative risk of PCa mortality $(95 \% \mathrm{Cl})$} & \multicolumn{2}{|c|}{ Relative risk of mortality due to causes other than $\mathrm{PCa}(95 \% \mathrm{Cl})$} \\
\hline & ADT & Observation & ADT & Observation \\
\hline 1985-1994 (70-79y) & $1.70(1.29-2.23)$ & 1.00 (ref) & $1.22(1.00-1.49)$ & 1.00 (ref) \\
\hline 1995-2004 & $1.55(1.31-1.84)$ & 1.00 (ref) & $1.07(0.97-1.18)$ & 1.00 (ref) \\
\hline $2005-2014$ & $2.71(2.08-3.53)$ & 1.00 (ref) & $1.03(0.92-1.16)$ & 1.00 (ref) \\
\hline 1985-1994 (>80y) & $1.30(0.89-1.88)$ & 1.00 (ref) & $1.09(0.85-1.39)$ & 1.00 (ref) \\
\hline 1995-2004 & $1.49(1.13-1.97)$ & 1.00 (ref) & $1.05(0.92-1.20)$ & 1.00 (ref) \\
\hline 2005-2014 & $1.65(1.19-2.29)$ & 1.00 (ref) & $1.06(0.91-1.23)$ & 1.00 (ref) \\
\hline
\end{tabular}

$p$-value for age-period interaction $=0.237 ; p$ for age effect $=0.052 ; p$ for period effect $=0.005$. Analysis is based on propensity matched pairs $P C a$ prostate cancer, $C l$ confidence interval, $A D T$ androgen deprivation therapy, ref. reference 
Age at diagnosis $70-79$
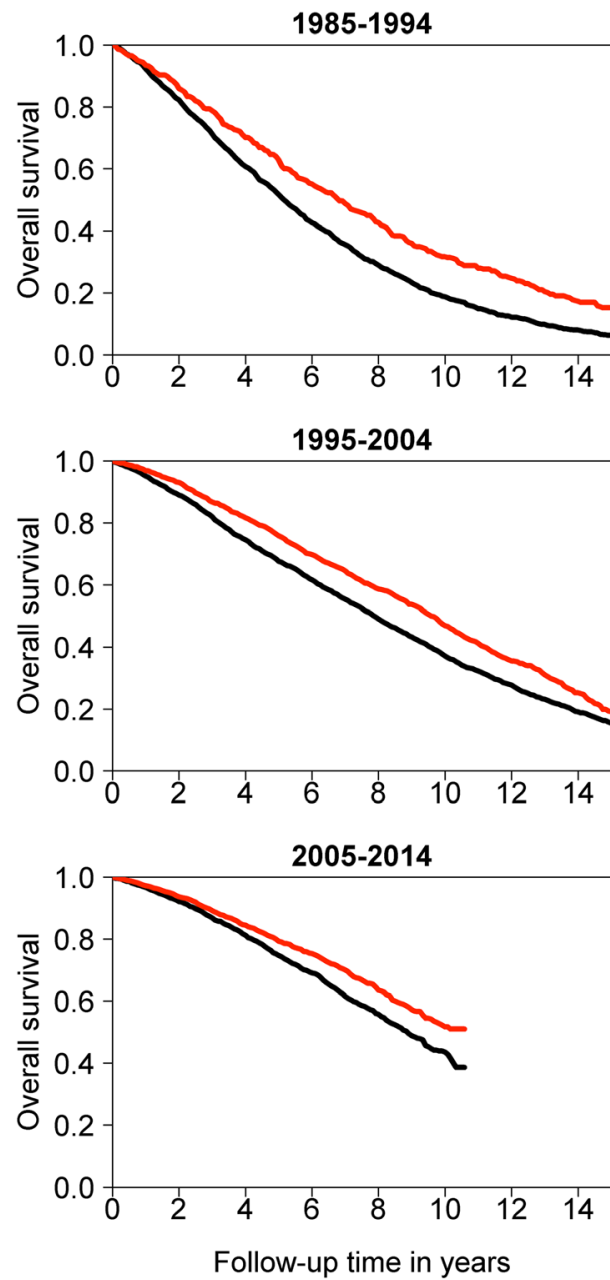

Age at diagnosis $80+$

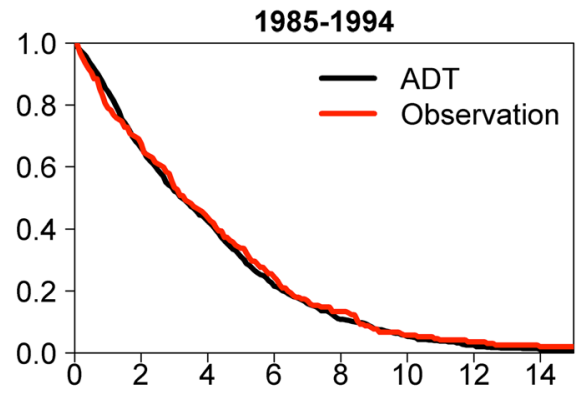

1995-2004

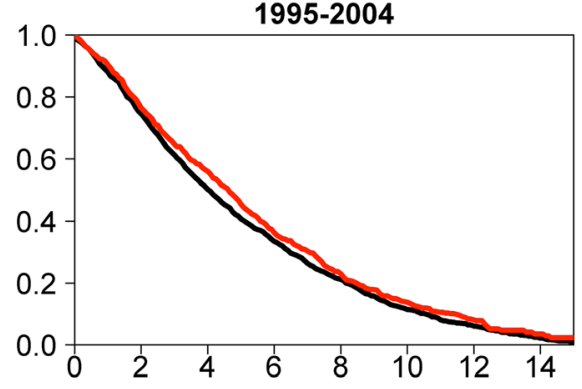

2005-2014

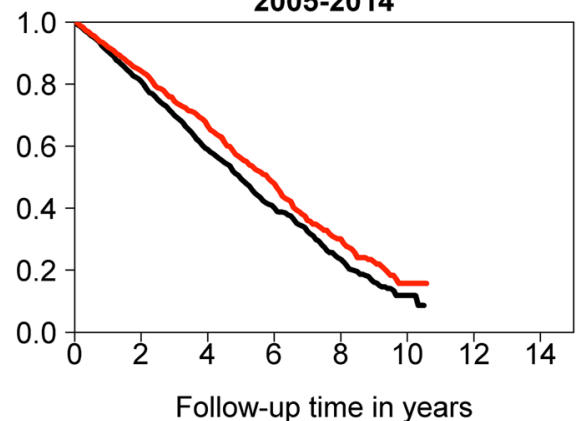

Fig. 1 Overall survival among men aged 70-79years and among men aged 80 or older

conclusion from this finding owing to the absence of data on patient comorbidities. However, increased morbidity and mortality from ADT-related side effects is possible. Thus, the survival benefits of ADT are partly offset by its high toxicity. These findings can also be explained by a better general health condition among patients in the observation group. In our cohort, patients in the observation group had a clearly lower risk of overall mortality compared to patients undergoing primary ADT. Since in epidemiological studies the only endpoint that is free from bias is mortality, we can assume that patients in observation cohort were healthier than those in the ADT cohort.

Many population-based analyses suggest that gonadotropin-releasing hormone $(\mathrm{GnRH})$ agonist use is associated with a greater risk of coronary artery disease, myocardial infarction, and diabetes mellitus (DM) [1719]. Subsequent reports have suggested that male patients with comorbidities or prior cardiovascular disease treated with $\mathrm{GnRH}$ agonists might be at increased risk of cardiovascular mortality [20,21]. Based on these observations, a science advisory consensus statement on $\mathrm{GnRH}$ agonist therapy and cardiovascular risk was issued, together with a U.S. Food and Drug Administration safety warning to address concerns of increased risk of myocardial infarction, stroke, sudden cardiac death, and DM [22]. However, conflicting results have been reported. In a recent meta-analysis, ADT use was not associated with an increased risk of cardiovascular death, but with a lower risk of PCSM and all-cause mortality [23]. Studer et al. also reported that ADT for localized PCa may even reduce cardiovascular mortality if started immediately after diagnosis [24].

The current study findings did not support the lifeprolonging effects of primary ADT for localized PCa. Several reports have shown similar results: In a prior 
population-based cohort study on 66,717 Medicare patients diagnosed between 1992 and 2009, and who received no definitive local therapy within 180 days of prostate cancer diagnosis, primary ADT was not associated with improved overall long-term CSS or the CSS of patients with localized $\mathrm{PCa}$ [25]. Instead, there is evidence that primary ADT led to inferior outcomes [24]. Low overall survival rates were reported for male patients with localized disease treated with primary ADT rather than observation in a previous population-based study [26]. In addition, Potosky et al. reported that primary ADT was neither associated with an enhanced risk of all-cause mortality (hazard ratio [HR] of 1.04, 95\% CI: 0.97-1.11) nor PCa-specific mortality (HR of 1.03; 95\% CI: 0.89-1.19) after adjusting for the sociodemographic and clinical characteristics of patients with localized PCa. However, primary ADT was associated with a decreased risk of all-cause mortality, but not PCSM, among patients at high risk of PCa progression [27].

PSA screening practices have increased exponentially over a 30-year period, and regular PSA testing is used frequently among all socioeconomic groups in Scandinavia and Finland [28, 29]. In the early years of the present study, a diagnosis of localized PCa was generally performed via a digital rectal examination or using pathological specimens obtained following a transurethral resection of the prostate. In recent years, most localized PCa cases have been diagnosed by prostate biopsies prompted by elevated PSA values. Moreover, although a proven benefit of the PSA screening of older males has not been shown, PSA testing is frequently performed for elderly patients [30]. The wide-stage migration of PCa from advanced to indolent disease has been reported over $\geq 20$ years [31]. Thus, a commonly employed but poorly organized screening policy explains the increased rate of $\mathrm{PCa}$ in past decades in Finland. Consequently, the number of elderly male patients with $\mathrm{PCa}$ has also increased. This implies that the more favorable outcomes associated with the use of primary observation compared to ADT in patients with $\mathrm{PCa}$, especially those in their 70s, can be attributed to PSA-related "lead time" rather than life extension.

Over the study period, staging of metastatic disease in Finland was performed by bone scan examination according to national guidelines until the mid-2000s, after which low-risk PCa patients typically underwent no imaging. The proportion of de novo metastatic $\mathrm{PCa}$ in Finland was nearly one-third from 1985 to 1994. This implies that staging procedures of $\mathrm{PCa}$ by bone scans were widely performed even in the earlier years of the study period, suggesting a good quality of the TNM classification data of $\mathrm{PCa}$ in the Finnish Cancer Registry database. In the Finnish Cancer Registry reports, the proportion of de novo metastatic PCa has recently been around 17\%, higher than in Sweden [32], where the incidence of $\mathrm{PCa}$ is high and PSA screening is widely performed. This might also indicate a more aggressive $\mathrm{PCa}$ histology in cases that are classified as localized by the TNM system, and thus more commonly treated with immediate ADT than cases with less aggressive histology.

A few points are worthy of further consideration. As information on patient comorbidities and detailed $\mathrm{PCa}$ characteristics (i.e., Gleason scores and PSA values) was not collected, it was not possible to adjust for differences in morbidity and mortality with a potential link to ADT. Thus, a comparison of study outcomes in terms of PCSM and overall survival between the different groups was not possible. Also, due to the absence of data on patient comorbidities and $\mathrm{PCa}$ characteristics, it was not possible to determine who would benefit from primary ADT in localized PCa. However, propensity score matching, particularly when applied to socioeconomic status/education level, may have mitigated some of the comorbidity-related limitations. Detailed information on cancer treatment was also incomplete for both treatment groups. Although men in the observation group did not receive $\mathrm{ADT}$ or radical treatment in the four months following diagnosis, it is conceivable that some of them may have received treatment later. This limitation may have had a substantial effect on the study outcomes. Furthermore, although the study population included patients with localized $\mathrm{PCa}$, the reliability of the staging procedures over time is debatable. TNM staging was based on mandatory reports obtained from hospitals and pathological laboratories. In other words, clinical practices in Finland were governed by national and/or European prostate cancer guidelines of the time. Consequently, the risk of metastases was evaluated according to these guidelines.

Notwithstanding these limitations, the study had several strengths. It was an observational population-based study estimating trends in cancer survival and mortality over time. While we did not directly compare different types of cancer treatments, population-based cohorts yield important information about $\mathrm{PCa}$ treatment in real-life situations, as the populations in randomized controlled trials are selected using stringent criteria by excluding out substantial proportion of real-life patients. However, in population-based studies patients are also allocated to different treatments, and results based on those can be subject to errors when comorbidities are involved. From an epidemiological perspective, these data determine the Finnish results obtained for patients managed with primary ADT or by observation. This study was based on nationwide data for $\mathrm{PCa}$ and included nearly $100 \%$ of patients in Finland over a nearly 30 -year period. No previous population-based results from Finland on this subject have been published. Similar complete population-based coverage is not available in many European countries. 


\section{Conclusion}

Primary ADT within four months period from diagnosis is not associated with improved long-term overall survival or decreased PCSM than primary conservative management for men with localized PCa. However, the study's results may have been affected by patient selection or treatment intention as a consequence of general health and healthcare service-related factors.

\section{Supplementary information}

Supplementary information accompanies this paper at https://doi.org/10. 1186/s12894-020-00593-7.

Additional file 1: Table S1. Stage distribution of prostate cancer patients by TNM-classification in Finland from 1985 to 2014

\section{Abbreviations}

ADT: androgen deprivation therapy; PCa: prostate cancer; PCSM: prostate cancer-specific mortality; RR: relative risk; SMR: standardized mortality ratio

\section{Acknowledgements}

Not applicable.

\section{Authors' contributions}

$A K, P B, N M$, and JP designed the study. HS and KS performed the data acquisition. KS, HS, and JP analyzed and interpreted the data regarding prostate cancer and androgen deprivation therapy. HS, AK, and NM wrote the manuscript draft. AK, NM, JP, and PB revised the text for important intellectual content. AK, PB, and NM supervised the work. All authors read and approved the final manuscript.

\section{Funding}

None.

\section{Availability of data and materials}

The datasets used and/or analyzed during the current study are available from the corresponding author upon reasonable request.

\section{Ethics approval and consent to participate}

The study protocol was approved by the institutional review board of the Hospital District of Southwest Finland (Study number: ETMK:116/1802/2014). The National Institute for Health and Welfare (Finland) approved access to the registry data (study number 182/5.05.00/2015). Statistics Finland approved access to the data on the cause of death (study number TK-53-86-17).

\section{Consent for publication}

Not applicable.

\section{Competing interests}

The authors declare that they have no competing interests.

\section{Author details}

'Department of Surgery, Central Hospital of Central Finland, Jyväskylä, Finland. ${ }^{2}$ Department of Urology, Turku University Hospital, Turku, Finland. ${ }^{3}$ Department of Urology, University of Turku, Turku, Finland. ${ }^{4}$ Finnish Cancer Registry, Helsinki, Finland. ${ }^{5}$ Faculty of Social Sciences (Health Sciences), Tampere, Finland. 'Department of Public Health, University of Helsinki, Helsinki, Finland. ${ }^{7}$ School of Health Sciences, University of Tampere, Tampere, Finland. ${ }^{8}$ Department of Urology, Tampere University Hospital, Tampere, Finland.
Received: 9 August 2019 Accepted: 27 February 2020

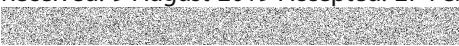

\section{References}

1. Huggins C, Stevens R, Hodges C. Studies on prostatic cancer: II. The effects of castration on advanced carcinoma of the prostate gland. Arch Surg. 1941:43(2):209-23.

2. European Association of Urology Guidelines. 2018 Edition. ESTRO - ESUR SIOG Prostate Cancer Guidelines Panel. EAU - ESTRO - ESUR - SIOG Guidelines on Prostate Cancer. Available from: [https://uroweb.org/ guideline/prostate-cancer/]. Accessed 3 June 2019.

3. Ryan CJ, Small EJ. Early versus delayed androgen deprivation for prostate cancer: new fuel for an old debate. J Clin Oncol. 2005;23(32):8225-1.

4. Cooperberg MR, Grossfeld GD, Lubeck DP, Carroll PR. National practice patterns and time trends in androgen ablation for localized prostate cancer. J Natl Cancer Inst. 2003;95(13):981-9.

5. Basaria S, Bhasin S. Targeting the skeletal muscle-metabolism axis in prostate-cancer therapy. N Engl J Med. 2012;367(10):965-7.

6. Lu-Yao GL, Albertsen PC, Moore DF, Shih W, Lin Y, DiPaola RS, et al. Survival following primary androgen deprivation therapy among men with localized prostate cancer. JAMA. 2008;300(2):173-81.

7. Chodak GW, Thisted RA, Gerber GS, Johansson JE, Adolfsson J, Jones GW, et al. Results of conservative management of clinically localized prostate cancer. N Engl J Med. 1994:330(4):242-8.

8. Kattan MW, Cuzick J, Fisher G, Berney DM, Oliver T, Foster CS, et al. Nomogram incorporating PSA level to predict cancer-specific survival for men with clinically localized prostate cancer managed without curative intent. Cancer. 2008;112(1):69-74.

9. Johansson JE, Andren O, Andersson SO, Dickman PW, Holmberg L, Magnuson A, et al. Natural history of early, localized prostate cancer. JAMA. 2004:291(22):2713-9.

10. Leinonen MK, Miettinen J, Heikkinen S, Pitkaniemi J, Malila N. Quality measures of the population-based Finnish Cancer registry indicate sound data quality for solid malignant tumours. Eur J Cancer. 2017;77:31-9.

11. Cutler SJ, Ederer F. Maximum utilization of the life table method in analyzing survival. J Chronic Dis. 1958;8(6):699-712.

12. Ho D, Imai K, King G, Stuart E. Matching as nonparametric processing for reducing model dependence in parametric causal inference. Polit Anal. 2007;15(3):199-236.

13. popEpi: Functions for epidemiological analysis using population data. $R$ package version 0.2.1. http://cran.r-project.org/package=popEpi. Accessed 2 Apr 2019

14. Ho D, Imai K, King G, Stuart E. Matchlt: nonparametric preprocessing for parametric causal inference. J Stat Softw. 2011;42(8):1-28.

15. Lu-Yao GL, Albertsen PC, Moore DF, Shih W, Lin Y, DiPaola RS, et al. Outcomes of localized prostate cancer following conservative management. JAMA. 2009;302(11):1202-9.

16. Albertsen PC, Moore DF, Shih W, Lin Y, Li H, Lu-Yao GL. Impact of comorbidity on survival among men with localized prostate cancer. J Clin Oncol. 2011:29(10):1335-41.

17. Keating NL, O'Malley AJ, Smith MR. Diabetes and cardiovascular disease during androgen deprivation therapy for prostate cancer. J Clin Oncol. 2006; 24(27):4448-56.

18. Keating NL, O'Malley AJ, Freedland SJ, Smith MR. Diabetes and cardiovascular disease during androgen deprivation therapy: observational study of veterans with prostate cancer. J Natl Cancer Inst. 2010;102(1):39-46.

19. D'Amico AV, Denham JW, Crook J, Chen MH, Goldhaber SZ, Lamb DS, et al. Influence of androgen suppression therapy for prostate cancer on the frequency and timing of fatal myocardial infarctions. J Clin Oncol. 2007; 25(17):2420-5.

20. Saigal CS, Gore JL, Krupski TL, Hanley J, Schonlau M, Litwin MS. Androgen deprivation therapy increases cardiovascular morbidity in men with prostate cancer. Cancer. 2007;110(7):1493-500.

21. Nanda A, Chen MH, Braccioforte MH, Moran BJ, D'Amico AV. Hormonal therapy use for prostate cancer and mortality in men with coronary artery disease-induced congestive heart failure or myocardial infarction. JAMA. 2009:302(8):866-73.

22. Levine GN, D'Amico AV, Berger P, Clark PE, Eckel RH, Keating NL, et al. Androgen-deprivation therapy in prostate cancer and cardiovascular risk: a science advisory from the American Heart Association, American Cancer 
Society, and American urological association: endorsed by the American Society for Radiation Oncology. CA Cancer J Clin. 2010;60(3):194-201.

23. Nguyen PL, Je Y, Schutz FA, Hoffman KE, Hu JC, Parekh A, Beckman JA, Choueiri TK. Association of androgen deprivation therapy with cardiovascular death in patients with prostate cancer: a meta-analysis of randomized trials. JAMA. 2011;306(21):2359-66.

24. Studer UE, Whelan P, Albrecht W, Casselman J, de Reijke T, Hauri D, et al. Immediate or deferred androgen deprivation for patients with prostate cancer not suitable for local treatment with curative intent: European Organisation for Research and Treatment of Cancer (EORTC) trial 30891. J Clin Oncol. 2006;24(12):1868-76.

25. Lu-Yao GL, Albertsen PC, Moore DF, Shih W, Lin Y, DiPaola RS, et al. Fifteenyear survival outcomes following primary androgen-deprivation therapy for localized prostate cancer. JAMA Intern Med. 2014;174(9):1460-7.

26. Wong YN, Freedland SJ, Egleston B, Vapiwala N, Uzzo R, Armstrong K. The role of primary androgen deprivation therapy in localized prostate cancer. Eur Urol. 2009;56(4):609-16.

27. Potosky AL, Haque R, Cassidy-Bushrow AE, Ulcickas Yood M, Jiang M, Tsai $\mathrm{HT}$, et al. Effectiveness of primary androgen-deprivation therapy for clinically localized prostate cancer. J Clin Oncol. 2014;32(13):1324-30.

28. Nordstrom T, Bratt O, Ortegren J, Aly M, Adolfsson J, Gronberg H. A population-based study on the association between educational length prostate-specific antigen testing and use of prostate biopsies. Scand J Urol. 2016;50(2):104-9.

29. Kilpelainen TP, Pogodin-Hannolainen D, Kemppainen K, Talala K, Raitanen J, Taari K, et al. Estimate of opportunistic prostate specific antigen testing in the Finnish randomized study of screening for prostate Cancer. J Urol. 2017; 198(1):50-7.

30. Vickers AJ, Sjoberg DD, Ulmert D, Vertosick E, Roobol MJ, Thompson I, et al. Empirical estimates of prostate cancer overdiagnosis by age and prostatespecific antigen. BMC Med. 2014;12:26.

31. Stamey TA, Caldwell M, McNeal JE, Nolley R, Hemenez M, Downs J. The prostate specific antigen era in the United States is over for prostate cancer: what happened in the last 20 years? J Urol. 2004;172(4 Pt 1):1297-301.

32. Westerberg M, Franck Lissbrant I, Damber JE, Robinson D, Garmo H, Stattin P. Temporal changes in survival in men with de novo metastatic prostate cancer: nationwide population-based study. Acta Oncologica. 2020;59(1): $106-11$.

\section{Publisher's Note}

Springer Nature remains neutral with regard to jurisdictional claims in published maps and institutional affiliations.

Ready to submit your research? Choose BMC and benefit from:

- fast, convenient online submission

- thorough peer review by experienced researchers in your field

- rapid publication on acceptance

- support for research data, including large and complex data types

- gold Open Access which fosters wider collaboration and increased citations

- maximum visibility for your research: over $100 \mathrm{M}$ website views per year

At $\mathrm{BMC}$, research is always in progress.

Learn more biomedcentral.com/submissions 